\title{
A pump-free microfluidic device for fast magnetic labeling of ischemic stroke biomarkers
}

\author{
Briliant Adhi Prabowo, Elisabete Fernandes*, Paulo Freitas* \\ INL - International Iberian Nanotechnology Laboratory, Braga 4715-330, Portugal \\ ORCiD BAP: orcid.org/0000-0002-7543-5143; EF: orcid.org/0000-0003-4558-7047; \\ PF: orcid.org/0000-0003-0015-1186 \\ *corresponding authors: elisabete.fernandes@inl.int; paulo.freitas@inl.int \\ Address: Av. Mestre José Veiga s/n 4715-330, Braga - Portugal \\ $\mathrm{T}:+351253140112$
}

Abstract

This research proposes a low-cost and simple operation microfluidic chip to enhance the magnetic labeling efficiency of two ischemic stroke biomarkers: cellular fibronectin (c-Fn) and matrix metallopeptidase-9 (MMP9). This fully portable and pump-free microfluidic chip is operated based on capillary attractions without any external power source and battery. It uses an integrated cellulose sponge to absorb the samples. At the same time, a magnetic field is aligned to hold the target labeled by the magnetic nanoparticles (MNPs) in the pre-concentrated chamber. By using this approach, the specific targets are labeled from the beginning of the sampling process without preliminary sample purification. The proposed study enhanced the labeling efficiency from $1 \mathrm{hr}$ to $15 \mathrm{~min}$. The dynamic interactions occur in the serpentine channel, while the crescent formation of MNPs in the pre-concentrated chamber, acting as a magnetic filter, improves the biomarker-MNP interaction. The labeling optimization by the proposed device influences the dynamic range by optimizing the MNP ratio to fit the linear range across the clinical cutoff value. The limit of detection (LOD) of $2.8 \mathrm{ng} / \mathrm{mL}$ and 54.6 $\mathrm{ng} / \mathrm{mL}$ of c-Fn measurement were achieved for undiluted and four times dilutions of MNP, respectively. While for MMP9, the LODs were $11.5 \mathrm{ng} / \mathrm{mL}$ for undiluted functionalized MNP and $132 \mathrm{ng} / \mathrm{mL}$ for four times dilutions of functionalized MNP. The results highlight the potential use of this device for clinical sample preparation and specific magnetic target labeling. When combined with a detection system could also be used as an integrated component of a point-of-care platform.

Keywords: Magnetic nanoparticle, microfluidic, sample preparation, fibronectin, MMP9, magnetoresistive. 


\section{Statements and Declarations}

This work was supported by Fundação para a Ciência e a Tecnologia (FCT) through project FIM4Stroke (reference PTDC/MEC-URG/29561/2017). All authors declare there are no conflicts of interest.

\section{Abbreviations Used}

c-Fn, cellular fibronectin; MMP9, matrix metallopeptidase 9; MNP, Magnetic nanoparticles; LOD, limit-of-detection; MR, magnetoresistive; rtPA, recombinant tissue plasminogen activator; PDMS, polydimethylsiloxane; PMMA, polymethyl methacrylate; CNC, computer numerical control; 2D, 2-dimensional; PVA, polyvinyl alcohol; PDMS-b-PEO, poly(dimethylsiloxane-b-ethylene oxide) methyl terminated; SD, standard deviation; RT, room temperature; PPC, pores per centimetre; PB, phosphate buffer; PB-T, phosphate buffer with $0.05 \%$ Tween ${ }^{\circledR} 20$; BSA, bovine serum albumin; DI, deionized. 


\section{Introduction}

Cerebrovascular accidents or stroke are a major disease-causing death worldwide in the last two decades after the ischemic heart attack[1]. Among the stroke cases, ischemic stroke type is responsible for up to $71 \%$ of cases globally[2]. Ischemic stroke can be defined as an episode of neurological dysfunction caused by focal cerebral, spinal, or retinal infarction[3]. The leading cause is a blood clot that blocks blood circulation to the brain. In acute ischemic stroke cases, the advanced treatment is recombinant tissue plasminogen activator (rt-PA), by intravenously drug delivery to dissolve the blood clot $(<4.5 \mathrm{hr})$ after the onset of the symptoms [2,4]. Despite the fact that around a quarter of ischemic stroke patients arrive at the hospital within the therapeutic time window, only $40 \%$ of these patients receive thrombolytic therapy with rt-PA $[5,6]$. This is due to the inability to accurately predict who will beneficiate from the treatment without suffering severe side effects, like hemorrhagic transformation (HT), which causes significant morbidity and mortality in stroke patients. The identification of those individuals that are likely to benefit from the therapy is dependent on a rapid and accurate diagnosis, which has not been developed yet. A set of protein biomarkers present in blood at certain concentrations have revealed the potential to predict the right candidates for rt-PA treatment[2, 7]. Cellular fibronectin (c-Fn) and matrix metallopeptidase 9 (MMP9) are biomarkers associated with the acute cases and relevant for patient stratification[5-9]. Besides recently, we performed a clinical study using a magnetoresistive (MR) biochip platform that has proven to detect within the clinical and relevant dynamic range those biomarkers[10]; the sample preparation is still a crucial step and very time-consuming. After separating serum from blood, the magnetic labeling of the target is performed inside a $1.5 \mathrm{~mL}$ Eppendorf ${ }^{\mathrm{TM}}$ tube that requires an incubation time of up to $1 \mathrm{hr}$, therefore limiting the delivery of fast results.

Microfluidic chips are potential devices for sample preparation due to the low volume sample handling, biocompatibility, low-cost material and fabrication, disposable and simple operation. Several studies reported the biochemical sample handling using microfluidic and magnetic beads to capture protein markers $[9,10]$. In addition, one of the notable reports proposed a magnetic susceptibility-based protein detection using magnetic levitation[11]. However, large equipment, such as an optical microscope, is still required to observe the particle bindings. Therefore, this approach will be challenging to use on stroke patient stratification, which requires a fully portable device and preferable equipment free, such as to avoid the utilization of a pump or bulky detection system. 
Several studies reported various principles of driven flow of microfluidic devices to reduce the dependency of the bulky pump, such as surface tension method[12], osmotic pressure[13], and mini-pump lid. Nevertheless, several limitations of these technologies are not suitable to the biochemical assay used for stroke patient samples. First, the clinical sample waste will be preferable to be handled as simple as possible. Second, the passive pump will be favorable for the battery and power-free purpose. Third, the required assay should be compatible with the practical use of conventional assay methods in hospitals. For example, the osmotic solution such as $\mathrm{NaCl}$ buffer is not preferable[13].

Another popular method to avoid the requirement of an electric pump in the microfluidic system is the capillary-driven chip[11, 14-16]. The capillary attraction can be driven by porous or cellulose materials, such as thread, woven fabrics, paper[17-22], and cellulose sponges[16, 23, 24]. Besides the low-cost and environmentally friendly materials, the cellulose-based capillarity also has a practical feature to handle liquid waste after the experiments.

To improve the magnetic target labeling and decrease the laborious work of the operator during the experiment, we developed a simple, miniaturized and pump-free microfluidic chip for sample preparation to precede the MR detection system. The flow was driven by two-step micro capillarity, by hydrophilic serpentine channel and a sponge for sample waste absorbent. We demonstrate that is possible to magnetically label the interested target in 15 min not compromising the number of protein biomarkers detected by the MR biochip platform. The simplicity of the microfluidic chip shows the potential of using it in conventional laboratories at the hospital for a first biomarker screening.

\section{Materials and method}

A simple microfluidic chip was developed to enhance the efficiency of magnetic labeling to the c-Fn and MMP9. The illustration of the proposed sample preparation chip is depicted in Fig. 1. The microfluidic was designed to be simple, pump-free, electric power free, requiring low-cost material and fabrication, miniaturized size, and disposable.

\section{Fig. 1 is preferred in this location}

\subsection{Microfluidic chip fabrication}

The mold of the sample preparation chip was designed using the 2-dimensional (2D) vector software (ArtCAM ${ }^{\circ}$ v.2011, Autodesk Inc.) aiming to have a total size of $75 \times 25 \times 5 \mathrm{~mm}$ 
and containing an inlet and outlet with a diameter of $7 \mathrm{~mm}$ and a height of $2 \mathrm{~mm}$. The serpentine channel width and thickness are $500 \mu \mathrm{m}$ and $150 \mu \mathrm{m}$, respectively; the total length of the channel (including the bending regions) is around $100 \mathrm{~mm}$. The pre-concentrated chamber was designed with $10 \mathrm{~mm}$ of diameter and $150 \mu \mathrm{m}$ of thickness. The final design of the mold was optimized and simulated for the engraving by end mills (Atis, Spain) cutter with diameter size of 0.8 and $1.5 \mathrm{~mm}$, to compromise the parameters, such as the engraving speed, sequence, resolution, tolerance, and smoothness of rotation speed of the end mills.

Subsequently, the design was exported to the computer numerical control (CNC) highspeed milling machine (Flexicam Viper 606, FlexiCAM GmbH, Germany). The transparent Polymethyl methacrylate (PMMA) plastic (Acrilico Cristal 10400, Plexicril, Portugal) with a thickness of $5 \mathrm{~mm}$ was prepared to be engraved as the molding. Next, the fabricated mold was cleaned by a wire brush following by the rising by isopropyl alcohol (Sigma Aldrich, Merck $\mathrm{KGaA}$, Germany) and $\mathrm{N}_{2}$ gas blowing. The final mold was then inspected under the microscope (Wide-Field Upright, Nikon-Ni-E, Japan) to examine the quality of the structure (Figure S1).

A PMMA plastic for the magnetic disc holder with a diameter of $15 \mathrm{~mm}$ and a thickness of $2 \mathrm{~mm}$ was also fabricated using a milling machine. Later, a disc-shaped magnet (supermagnet, Webcraft GmbH, Germany) was attached inside the cylindrical hole of the PMMA.

Polydimethylsiloxane (PDMS) elastomer chemicals (Dowsil ${ }^{\mathrm{TM}} 184$ Silicone Elastomer, Dow Chemical, US) with a ratio of 10:1 were mixed (3 min, room temperature/RT) and followed by degassing in the vacuum to remove the air bubbles. Next, the PDMS was cast to the mold to cover all the structures up to the same level of inlet and outlet thickness, before the curing process in the oven $\left(2 \mathrm{hrs}, 65^{\circ} \mathrm{C}\right)$. The hardened PDMS was cut and peeled off from the mold. The channel patterned PDMS and a cleaned soda glass substrate with a size of $75 \times 25 \times 1$ mm (Epredia ${ }^{\mathrm{TM}}$ Microscope Slides, Thermo Scientific, US) were exposed by plasma $\mathrm{O}_{2}$ (Expanded Plasma Cleaner PDC-002, Harrick Plasma, US) for 40 seconds. The patterned PDMS immediately bond to the glass substrate with an assisted uniform pressure to all the PDMS surfaces.

\subsection{Hydrophilicity treatment of the chips}

The hydrophilicity treatment of the microfluidic channel was tested by using three different methods, i.e., channel passivated chip using: (1) 10\% polyvinyl alcohol (PVA), herein this chip is termed as PVA-chip; (2) poly(dimethylsiloxane-b-ethylene oxide) methyl 
terminated (PDMS-b-PEO), mentioned as PEO-chip; and (3) the last method is by the additional $1 \%$ of PDMS-b-PEO while preparing the PDMS mixing, herein mentioned as PEOm-Chip.

The PVA (Sigma Aldrich 363073, Merck KGaA, Germany) was prepared in deionized (DI) water of $10 \%$ dilution; then, it was magnetically stirred for $40 \mathrm{~min}$ at RT. Next, the temperature was gradually increased to $100{ }^{\circ} \mathrm{C}$ for another $40 \mathrm{~min}$ on the stirrer, followed by 8 hrs of stirring at $65{ }^{\circ} \mathrm{C}$. The PDMS-b-PEO (PDMS-b-PEO 09780-100, Polysciences Europe $\mathrm{GmbH}$, Germany) was diluted in the DI water with a concentration of $1 \%$ following by stirring the solution at RT for 15 min. The prepared PVA (or PDMS-b-PEO) solution was dropped in the inlet of the different fabricated chips, around $100 \mu \mathrm{L}$, respectively. Next, the chip was stored in the hot plate for $30 \mathrm{~min}$ at $40^{\circ} \mathrm{C}$, then $100{ }^{\circ} \mathrm{C}$ for PVA. For PDMS-b-PEO the chip was stored at $65{ }^{\circ} \mathrm{C}$ in the oven until dry, then this process was repeated three times. After the third drop of chemical passivation, the chip was stored in the oven $\left(8 \mathrm{hrs} ; 65^{\circ} \mathrm{C}\right)$. Finally, the PVA-chip and PEO-chip were ready for the labeling process or can be stored at room temperature storage.

The third chip (PEO-m-chip) was prepared with a different recipe of PDMS mixing compared to previous chips. First, when the PDMS elastomer was mixed with a ratio of 10:1, additional drops of PDMS-b-PEO were added with a ratio of $1 \%$ from the total mixing volume. Next, the consecutive process was identical to the untreated chips, such as degassing, casting, curing, cutting, peeling, and bonding to glass by plasma $\mathrm{O}_{2}$. Then, PEO-m-chip was obtained and ready for the labeling process. For the sample's capillary attraction to the chip's outlet, the ultra-fine PVA-sponge sheet (RamerFoam UD grade, Ramer Ltd., UK) with the density of the pores around 30 PPC (pores per centimeter) were cut into cylindrical shapes with a diameter of $10 \mathrm{~mm}$. The cylindrical sponge is aligned to the outlet after the sample fulfills the preconcentrated chamber.

\subsection{Magnetic nanoparticle functionalization}

The magnetic labeling functionalization was described in detail previously[8]. Briefly, Streptavidin-conjugated 250-nm magnetic nanoparticles (MNPs) $\left(2 \mu \mathrm{L}\right.$ of $4.9 \times 10^{11} \mathrm{~mL}^{-1}$, Nanomag, Micromod, Germany) were incubated for $1 \mathrm{~h}$ with $50 \mu \mathrm{g} / \mathrm{mL}$ of $60 \mu \mathrm{L}$ biotinylated polyclonal antibodies (Immunostep, Spain) of c-Fn or MMP9 (prepared in phosphate buffer with $0.05 \%$ Tween ${ }^{\circledR 20}$, PB-T). Next, the MNPs surface was blocked for $1 \mathrm{~h}$ with bovine serum albumin (BSA) 5\% in PB. Subsequently, the MNPs stock solution was ready to use and diluted four times. The undiluted and the diluted stock solution is termed 1:1 and 1:4 MNP, 
respectively. The MNPs of 1:1 or 1:4 were dropped together with the protein biomarker, c-Fn or MMP9, in the inlet of the microfluidic chip in a total volume of $100 \mu \mathrm{L}$ (Fig. 1A).

\subsection{Detection of MNP-labeled biomarkers on the magnetoresistive biochip}

The MNP-labeled biomarkers obtained in the outlet (Fig. 1B) of the microfluidic chip were loaded through an array of $30 \mathrm{U}$-shaped spin-valve (SV) sensors microfabricated and functionalized (Figure S2) as described previously [25-28]. The detection strategy was based on a sandwich assay format, where primary monoclonal antibodies (probes) were immobilized on the top of the gold layer of the SV sensors to specifically capture the MNP-labeled biomarkers. A magnetic focusing (MF) of 2 min was applied to enhance the contact between probes and labeled biomarkers. Then, after $30 \mathrm{~min}$ incubation, the sample was washed away to remove the unbound biomarkers. The number of MNP-labeled targets captured at each sensor surface is obtained by the normalized sensor signal ( $\Delta$ Vbinding/ Vsensor), where the $\Delta$ Vbinding is the difference between the end signal (after incubation and washed step) and the initial baseline.

\subsection{Statistical analysis}

The data presented for each concentration is related to the average of the signal obtained from at least 20 different sensors, measured simultaneously in real-time, from a maximum of 30 sensors available at the MR biochip. The propagation of errors from active sensings was utilized to calculate the average signal value and its standard deviation (SD). Hillslope model was applied for the curve fitting of the calibration curve with $95 \%$ of confidence level, 1000 data points, ANOVA, and up to 400 iterations. The confidence signal level of LOD (Y calculated by[29]:

$$
\mathrm{Y}_{\mathrm{LOD}}=1.645 \mathrm{SDC} 0+1.645 \mathrm{SDC} 1
$$

SDC0 and SDC1 are SD of blank sample and smallest concentration, respectively; subsequently, the YLOD value was substituted to the fitting curve to estimate the LOD concentration in $\mathrm{x}$-axis of the curve.

\section{Results and Discussion}

\subsection{Hydrophilicity and microfluidic chip performance}

After bonding to soda-lime glass, the fabricated microfluidic chips were tested for sponge capillary performance. When the first sample was loaded in the inlet of the original chip (without chemical treatment), the liquid automatically flowed to the serpentine channel due to 
the intrinsic hydrophilic properties of the serpentine channel created by the plasma $\mathrm{O}_{2}$ treatment before the PDMS bonding to the glass. The plasma $\mathrm{O}_{2}$ induced radical species of silanol groups (Si-OH), alcoholic hydroxyls $(\mathrm{C}-\mathrm{OH})$, and carboxylic acids $(\mathrm{COOH})[30,31]$. This rich $-\mathrm{OH}$ surface is critical for covalently bonding to the soda-lime glass substrate, which also contains substantially $-\mathrm{OH}$ groups due to its composition formed by amorphous $\mathrm{SiO}_{2}$ up to 70\%[32]. Figure S3 and video V1 in the supplementary materials depicted the assessment of hydrophilicity and capillarity of the fresh-fabricated device without any hydrophilicity treatment.

The abundance of $-\mathrm{OH}$ atoms on the surface of the channel and walls[33] maintains the hydrophilic properties which attract the capillarity of the sample delivery to fulfill the preconcentration chamber. Once the sample complies with the pre-concentrated chamber and is attracted by the sponge, the absorption into the sponge occurs in less than 3 minutes. The flow rate was noted around 30 to $50 \mu \mathrm{L} / \mathrm{min}$. The hydrophilic properties of the channel remained for up to 2 days, which is not useful for the long-term preservation of the device. This short lifetime of the hydrophilic surface can be explained by the gradual release of - $\mathrm{OH}$ groups from the $\mathrm{Si}$ atom of the PDMS surface[34]. Thus, to improve the hydrophilicity lifetime of the channel, the PDMS was passivated using PVA[30] (for PVA-chip), or PDMS-b-PEO[35-37] (for PEOchip), also using additional 1\% PDMS-b-PEO materials during the material mixing of the PDMS, before the casting to the mold (for PEO-m-Chip) (Table 1).

The PVA passivation treatment of the PVA-chip can be explained by the nature of covalent bonding between $-\mathrm{OH}$ groups (in the PDMS channel) and $-\mathrm{C}$ atoms (in the PVA). Moreover, the device baking $\left(40-100^{\circ} \mathrm{C}\right)$ after the PVA passivation enhances the Oxygen scavenging process deeper inside the PDMS material, and the early bonding of $-\mathrm{OH}$ forms a stable $\mathrm{SiO}_{2}$ bond (Scheme $\mathrm{S} 1(\mathrm{~A})$ ). On the other side, the $-\mathrm{COOH}$ groups remain on the surface and are responsible for the hydrophilic characteristics[38]. The characteristic of the PVA-chip, achieves a flow rate of $4.8 \mu \mathrm{L} / \mathrm{min}$ and hydrophilicity lifetime of up to 2 months.

For the PDMS-b-PEO hydrophilicity treatment of the PEO-chip, the mechanism can be described by the Van der Waals force and hydrophobic interaction between both PDMS blocks (PDMS block of the channel and PDMS block of the PDMS-b-PEO). Furthermore, the baking of the chip $\left(65^{\circ} \mathrm{C}\right)$ induces the permanent binding of both PDMS blocks, while the PEO blocks remain on the surface to maintain the hydrophilicity of the channel (Scheme S1(B))[39].

In addition, for the PEO-m-Chip treatment, the mechanism can be slightly different. PDMS-PDMS binding blocks are started during mixing of the elastomer, curing, and the PDMS-b-PEO materials. Next, the baking process enhanced permanent crosslinked PDMS 
blocks, while the PEO side remains hydrophilic on the surface[36, 39]. Thus, the surface of the whole PDMS material is hydrophilic in a stable state. Consequently, this modified PDMS is hard to be controlled by the plasma $\mathrm{O}_{2}$ during the bonding process. Therefore, PEO-m-Chip has a weak bonding substrate and makes the potential leakage in the channel. The hydrophilicity lifetime of the proposed chip could be improved up to 2 months, with its different flow rates as presented in Table 1. The comparative performance of the microfluidic chips shown in Table 1 highlighted the importance of finding a compromise between the different variables, i.e., the flow rate of the channel capillarity, the device lifetime, and bonding quality of the chip to the glass substrate. The indicated flow rates were measured until the sample fulfills the pre-concentrated chamber. After this step, the flow rates of the chips have relied on the capillarity grade of the sponge. The channel flow rate plays a vital role in giving the MNP and the protein biomarkers enough time to bind each other. Therefore, the fast flow rate will not be preferable due to the lower probability of binding in incubation time. In consideration of medium flow rate ( $25 \mu \mathrm{L} / \mathrm{min}$ ), hydrophilicity lifetime up to 2 months, and non-leakage channel of the chip, the PEO-chip showed the required properties to perform the magnetic labeling assay in our study. The PEO-chip evaluation is presented in Figure S3.

The magnetic disc for the MNP concentrator is preferable with a diameter slightly larger $(15 \mathrm{~mm})$ than the pre-concentrated chamber $(10 \mathrm{~mm})$; due to the strongest magnetic fields near the edge of the magnet, a crescent formation of the concentrated MNP appears gradually in the pre-concentrated chamber (Figure S4 (a)). This crescent formation can enhance the filtration ability and gradually capture the target molecules accumulated to the pre-concentrated chamber. Simple repetitive slides of the chip over the magnet were performed to mix and drive the concentrated MNP to the outlet. The experimental principle and device operation can be seen in detail in video $\mathrm{V} 2$ of supplementary files.

\section{Fig. 2 is preferred in this location}

\section{Table 1 is preferred in this location}

\subsection{Efficiency of magnetic labeling on-chip}

The high-efficiency labeling is a critical factor for our research in terms of time and the amount of captured targets. This purpose is relevant to the short time of the symptom onset of the stroke patients before the rtPA treatment. 
The labeling on-chip illustrated in Fig. 2 was performed in less than 15 mins, starting from the sample loading in the inlet until the MNP extraction in the outlet, where MNPs are ready to use on the MR biochip platform. The efficiency of the magnetic labeling on-chip was compared with the conventional magnetic labeling (performed by the operator and using a 1.5 $\mathrm{mL}$ Eppendorf ${ }^{\mathrm{TM}}$ tube) by analyzing the detection of MNP-labeled targets on the MR biochip. For that, 30 spin-valve sensors were functionalized, 15 sensors with the antibodies to capture the specific target c-Fn, and another 15 sensors used as control (with 5\% BSA). The conventional and the labeling on-chip were tested using a high concentration of c-Fn (10 $\mu \mathrm{g} / \mathrm{mL}$ ). The results (Fig. 3A) showed that the labeling on-chip process ( $\leq 15 \mathrm{~min}$ ) achieves a comparable signal level in the MR biosensor to the conventional labeling on-tube (1hr) from the previous reports[8, 40, 41].

While for the 15 min labeling on Eppendorf ${ }^{\mathrm{TM}}$, the signal level was significantly dropped around 50\%. The binding efficiency signals are demonstrated in Fig. 3A. Moreover, in Fig. 3B, we showed the correlation of channel height to the operation time and the binding efficiency from the MNP filtration in the pre-concentrated chamber. There is a trade-off between the operation time and labeling efficiency from the channel heights characterization. The higher the channel height, the faster sample absorption into the sponge leads to the faster operation time of the labeling. Nevertheless, the labeling efficiency drops with the increase of the channel sizes. It can be explained that with the higher channel height, the larger surface area of the sponge interacts with the liquid and enhances absorption speed. On the other hand, a smaller number of targets can be filtered by the MNPs cluster in the pre-concentrated chamber. In contrast, the shallower the channel height of the microfluidic device, the longer operation time is required for the labeling due to the lower absorption contact by the sponge. But it leads to better filtration by MNPs cluster. Based on these findings, the proposed microfluidic device with a channel height of 150 um achieves the optimized labeling efficiency with a reasonable operation time.

To assess the protein binding on MR biochip, the density of MNP-labeled biomarkers can be observed visually under microscopic inspection. The several MNPs clusters on the gold surface are represented by brownies (pointed out by arrows and other areas). In contrast, the control regions of the spin valve sensors (Fig. 4C and D) show clear areas from brownies spots of MNPs clusters. It shows that both labeling on-chip in $15 \mathrm{~min}$ proposed in this article can be comparable to the conventional labeling on Eppendorf ${ }^{\mathrm{TM}}$, by comparable numbers of brown spots of MNP binding in the sensor surface. 
Fig. 3 is preferred in this location

Fig. 4 is preferred in this location

\subsection{Ischemic strokes biomarkers detection in MR platform}

The stroke biomarkers c-Fn and MMP9 were used as the case study to test the microfluidic chip combined with the MR platform. The clinical cutoff values of the c-Fn and MMP9 in stroke patients' blood are $3.6 \mu \mathrm{g} / \mathrm{mL}$ and $140 \mathrm{ng} / \mathrm{mL}$, respectively[42, 43]. Consequently, for the detection in the MR platform, a dynamic range of the sensor across the clinical cutoff value plays a critical role in foreseeing an actual clinical case scenario.

The MR biosensor was exposed to a series of concentrations of labeled c-Fn from 1 $\mathrm{ng} / \mathrm{mL}$ to $10 \mu \mathrm{g} / \mathrm{mL}$ in $\mathrm{PB}$ buffer. Figure $5 \mathrm{~A}$ (square blue curve) shows that using undiluted MNP (MNP 1:1) concentration, the detection limit is about $2.8 \mathrm{ng} / \mathrm{mL}$ and reaches the saturation value in the concentration of $1 \mu \mathrm{g} / \mathrm{mL}$. This dynamic range does not fulfill the clinical requirement for c-Fn analysis. The saturation point is below the clinical cutoff value of 3.6 $\mu \mathrm{g} / \mathrm{mL}$, as indicated in the green dash line. The finding in our previous study[8] suggested that the concentration of the MNP and the magnetic focusing strategy can be tuned to adjust the dynamic range of the assay according to clinical needs. The 4 times dilutions of MNP (MNP 1:4 in Fig. 5A, square red curve) decreased the assay sensitivity by achieving the detection limit of $54.6 \mathrm{ng} / \mathrm{mL}$ and eliminating the saturation concentration at $1 \mu \mathrm{g} / \mathrm{mL}$.

Compared to our previous report[8], the c-Fn detection in this assay started from a very small concentration $(1 \mathrm{ng} / \mathrm{mL})$ in PB buffer, which was not explored before until this range. Therefore, the potential performance and applications of the labeling strategy combined with the MR biochip platform can be observed, especially for other protein biomarkers with low clinical cutoff values requirements. Moreover, we found that for small concentration values the labeling on-chip performs a slightly better MR signal compared to our previous study. This finding can be explained by: (1) the use of PB buffer on the dilution of c-Fn that decreases the nonspecific binding effect compared to the use of depleted-serum; (2) the use of a miniaturized magnetic labeling chip that increases the probability to capture protein biomarkers due to the dynamic interactions in the serpentine channel, where biomarker-MNP have more chance to interact; (3) the filtration by MNPs clusters (crescent-like formation) in the pre-concentrated chamber improves the probability to capture the target protein.

Fig. 5 is preferred in this location 
Furthermore, the MMP9 detection in an MR biochip platform using the proposed microfluidic chip for biomarker labeling is presented in Fig. 5B. The MMP9 biomarker labeling and detection are challenging due to its cutoff requirements and small molecular weight (95 $\mathrm{kDa})[44]$ compared to c-Fn (440 kDa)[45]. This last aspect influences the obtained calibration curve of MMP9 using undiluted MNP and MNP 1:4. The dynamic range when using undiluted MNP shows, across the concentration of clinical cutoff value, a significant linear range with a LOD of $11.5 \mathrm{ng} / \mathrm{mL}$. While when using MNP 1:4, the LOD was calculated around $132 \mathrm{ng} / \mathrm{mL}$, which is very close to the concentration of clinical cutoff value $(140 \mathrm{ng} / \mathrm{mL})$. Therefore, for patient stratification using the MNP 1:4, the quantification of MMP9 present in healthy patients will be very difficult. Thus, for MMP9 detection, the use of undiluted MNP particles during the labeling process is preferable.

\subsection{Overview and discussion of related technologies}

To summarize the discussion and potential feature of the proposed microfluidic chip, we reviewed a previously published study of microfluidics utilizing magnetic field for labeling or particle separation to understand the novelty and potential applications of our device. A comparative table of these related magnetic microfluidics devices is listed in Table 2.

Zordan et al. proposed disposable microfluidics for multiplexed detection of E. coli in SPR and fluorescence imaging[46]. In comparison, Lee et al. reported microfluidics for isothermal solid-phase amplification and detection of the DNA methylation in 65 mins of operation time[47]. Another method using 3D magnetic grid separation for Salmonella cells samples was reported by Hou et al., and it achieves operation time around $1 \mathrm{hr}[48]$. Tsai et al. proposed a magnetic field immunosensor by using a magnetic nanoparticle conjugated target immobilized on the microfluidic chip for IgG and carcinoembryonic antigen (CEA) samples. The sensing principle is quite simple and can be operated in less than 10 mins. The separation of paramagnetic and non-magnetic cells is demonstrated for capturing live cardiomyocytes in a microfluidic device. The combination of the magnetic field, gravity, and hydrodynamic force from buffer flow inside the channel separates the paramagnetic cells and the targeted cells at around 20 mins[49].

Another study presented a micromagnetic cell sorter for rapid capture target CD3+ T lymphocytes only around $20 \mathrm{~s}$. Two permanent magnets are located on the opposite sides of the channel to deviate the flow of the biomarkers labeled by micromagnetic particles[50]. Furthermore, the Baeumner group presented magnetic labeling of nanovesicles on 
microfluidics devices in 15 mins of operation time[51]. Another rapid capture of circulating tumor cells (CTC) of COLO205 and SKBR3 was reported in microchip-based immunomagnetic in $15 \min [52]$.

Microfluidic for cell separation from blood was demonstrated for the targeted white blood cell (WBC) for 4 min operation[53]. Subsequently, the non-lithography microfluidics was utilized for a multiplexed cancer biomarker screening of IL-6 and IL-8 around $30 \mathrm{~min}[54]$. In addition, a portable, fully integrated, and miniaturized cytometer chip were used to stratification of WBC and Red blood cell (RBC) in $5 \min$ [55]. Vojtíšek et al. reported the DNA hybridization on a microfluidics chip for $1 \mathrm{~min}$ operation time[56]. Nevertheless, the mentioned reports above are still dependent on using the pump, and the typical disposable part is the microfluidic device itself.

Interestingly, the proof-of-concept of the whole disposable sample preparation chip was demonstrated by Liang et al. [57]. This study reported single magnet manipulation for 3D focusing ferromicrofluidics. In addition, microfluidic devices were reported utilized for magnetophoresis for particle and cells separation. In this study, the Saccharomyces cerevisiae was used as a target biomolecule[58]. These studies are good examples of the whole disposable chip for sample preparation. Nevertheless, these proofs-of-concept require magnetophoresis assay, where the captured target relies on the magnetic nanoparticle label followed by measurement to quantify the result.

The comparison of using proposed microfluidics for sample preparation in our study is strongly correlated to the screening of ischemic stroke biomarkers, especially for the potential application using clinical samples. Based on this purpose, this article emphasizes a microfluidic device with no additional equipment required, i.e., a pump and power source for simple operation and disposable format. It provides target labeling in less than $15 \mathrm{~min}$ and is strongly correlated with a portable MR biochip platform, in which sensors are sensitive to small magnetic fields generated by the MNPs. On the other hand, these MNPs allow the capture and concentration of the interesting target from the complex sample matrix (serum), obtained, in our device, by manipulation of magnetic field using a permanent magnet.

\section{Table 2 is preferred in this location}

\section{Conclusion}

In summary, we developed a microfluidic chip to perform high efficiency of magnetic labeling of ischemic stroke biomarkers, c-Fn, and MMP9, for the following detection by an 
MR biochip platform. By using the proposed magnetic labeling on the pump-free microfluidic chip, the incubation time can be reduced from $1 \mathrm{hr}$ down to $15 \mathrm{mins}$. The efficiency of the labeling time is very critical for the screening of biomarkers of acute ischemic stroke patients because of the short therapeutic time-window (within the $4.5 \mathrm{hr}$ ). Moreover, the proposed labeling on-chip process is equipment-free (pump and power supply-free), provided in a miniaturized size, with a simple operation and sample handling, disposable, and low cost. Therefore, the proposed device has the potential to be integrated with a detection system based on MNPs and used as a point-of-care platform for the fast screening of biomarkers.

\section{References}

1. WHO (2021) Leading causes of death and disability: A visual summary of global and regional trends 2000-2019. https://www.who.int/data/stories/leading-causes-of-deathand-disability-2000-2019-a-visual-summary. Accessed 2 Jun 2021

2. Campbell BCV, De Silva DA, Macleod MR, Coutts SB, Schwamm LH, Davis SM, Donnan GA (2019) Ischaemic stroke. Nat Rev Dis Prim 5: . https://doi.org/10.1038/s41572-019-0118-8

3. Sacco RL, Kasner SE, Broderick JP, Caplan LR, Connors JJ, Culebras A, Elkind MSV, George MG, Hamdan AD, Higashida RT, Hoh BL, Janis LS, Kase CS, Kleindorfer DO, Lee JM, Moseley ME, Peterson ED, Turan TN, Valderrama AL, Vinters H V. (2013) An updated definition of stroke for the 21st century: A statement for healthcare professionals from the American heart association/American stroke association. Stroke 44:2064-2089 . https://doi.org/10.1161/STR.0b013e318296aeca

4. Emberson J, Lees KR, Lyden P, Blackwell L, Albers G, Bluhmki E, Brott T, Cohen G, Davis S, Donnan G, Grotta J, Howard G, Kaste M, Koga M, Von Kummer R, Lansberg M, Lindley RI, Murray G, Olivot JM, Parsons M, Tilley B, Toni D, Toyoda K, Wahlgren N, Wardlaw J, Whiteley W, Del Zoppo GJ, Baigent C, Sandercock P, Hacke W (2014) Effect of treatment delay, age, and stroke severity on the effects of intravenous thrombolysis with alteplase for acute ischaemic stroke: A meta-analysis of individual patient data from randomised trials. Lancet 384:1929-1935 . https://doi.org/10.1016/S0140-6736(14)60584-5

5. Orset C, Arkelius K, Anfray A, Warfvinge K, Vivien D, Ansar S (2021) Combination 
treatment with U0126 and rt-PA prevents adverse effects of the delayed rt-PA treatment after acute ischemic stroke. Sci Rep 11: . https://doi.org/10.1038/s41598021-91469-9

6. Orbán-Kálmándi R, Szegedi I, Sarkady F, Fekete I, Fekete K, Vasas N, Berényi E, Csiba L, Bagoly Z (2021) A modified in vitro clot lysis assay predicts outcomes and safety in acute ischemic stroke patients undergoing intravenous thrombolysis. Sci Rep 11: . https://doi.org/10.1038/s41598-021-92041-1

7. Wardlaw JM, Murray V, Berge E, Del Zoppo G, Sandercock P, Lindley RL, Cohen G (2012) Recombinant tissue plasminogen activator for acute ischaemic stroke: An updated systematic review and meta-analysis. Lancet 379: . https://doi.org/10.1016/S0140-6736(12)60738-7

8. Fernandes E, Sobrino T, Martins VC, Lopez-loureiro I, Campos F, Germano J, Rodríguez-Pérez M, Cardoso S, Petrovykh DY, Castillo J, Freitas PP (2020) Point-ofcare quantification of serum cellular fibronectin levels for stratification of ischemic stroke patients. Nanomedicine Nanotechnology, Biol Med 30:102287 . https://doi.org/10.1016/j.nano.2020.102287

9. Cowell TW, Valera E, Jankelow A, Park J, Schrader AW, Ding R, Berger J, Bashir R, Han HS (2020) Rapid, multiplexed detection of biomolecules using electrically distinct hydrogel beads. Lab Chip 20: . https://doi.org/10.1039/d0lc00243g

10. Kim S, Han S, Lee J (2017) Asymmetric bead aggregation for microfluidic immunodetection. Lab Chip 17: . https://doi.org/10.1039/c7lc00138j

11. Yaman S, Tekin HC (2020) Magnetic Susceptibility-Based Protein Detection Using Magnetic Levitation. Anal Chem 92: . https://doi.org/10.1021/acs.analchem.0c02479

12. Beebe DJ, Mensing GA, Walker GM (2002) Physics and applications of microfluidics in biology. Annu Rev Biomed Eng 4:261-286 . https://doi.org/10.1146/annurev.bioeng.4.112601.125916

13. Chuang CH, Chiang YY (2019) Bio-O-Pump: a novel portable microfluidic device driven by osmotic pressure. Sensors Actuators, B Chem 284:736-743 . https://doi.org/10.1016/j.snb.2019.01.020

14. Tan W, Powles E, Zhang L, Shen W (2021) Go with the capillary flow. Simple thread- 
based microfluidics. Sensors Actuators, B Chem 334: . https://doi.org/10.1016/j.snb.2021.129670

15. Lin YH, Chang CH (2021) Glass capillary assembled microfluidic three-dimensional hydrodynamic focusing device for fluorescent particle detection. Microfluid Nanofluidics 25: . https://doi.org/10.1007/s10404-021-02441-y

16. Zhou T, Yang J, Zhu D, Zheng J, Handschuh-Wang S, Zhou X, Zhang J, Liu Y, Liu Z, He C, Zhou X (2017) Hydrophilic Sponges for Leaf-Inspired Continuous Pumping of Liquids. Adv Sci 4: . https://doi.org/10.1002/advs.201700028

17. Ulum MF, Maylina L, Noviana D, Wicaksono DHB (2016) EDTA-treated cottonthread microfluidic device used for one-step whole blood plasma separation and assay. Lab Chip 16: . https://doi.org/10.1039/c6lc00175k

18. Jia C, Jiang F, Hu P, Kuang Y, He S, Li T, Chen C, Murphy A, Yang C, Yao Y, Dai J, Raub CB, Luo X, Hu L (2018) Anisotropic, Mesoporous Microfluidic Frameworks with Scalable, Aligned Cellulose Nanofibers. ACS Appl Mater Interfaces 10: . https://doi.org/10.1021/acsami.7b17764

19. Jang I, Carraõ DB, Menger RF, Moraes De Oliveira AR, Henry CS (2020) Pump-Free Microfluidic Rapid Mixer Combined with a Paper-Based Channel. ACS Sensors 5: . https://doi.org/10.1021/acssensors.0c00937

20. He Y, Gao Q, Wu W Bin, Nie J, Fu JZ (2016) 3D printed paper-based microfluidic analytical devices. Micromachines 7: . https://doi.org/10.3390/mi7070108

21. Ratajczak K, Stobiecka M (2020) High-performance modified cellulose paper-based biosensors for medical diagnostics and early cancer screening: A concise review. Carbohydr. Polym. 229

22. Purwidyantri A, Karina M, Hsu C-H, Srikandace Y, Prabowo BA, Lai C-S (2020) Facile bacterial cellulose nanofibrillation for the development of plasmonic paper sensor. ACS Biomater Sci Eng 6:3122-3131. https://doi.org/10.1021/acsbiomaterials.9b01890

23. Meng X, Dong Y, Zhao Y, Liang L (2020) Preparation and modification of cellulose sponge and application of oil/water separation. RSC Adv 10: . https://doi.org/10.1039/d0ra07910c 
24. Du Y, Cheng H, Li Y, Wang B, Mao Z, Xu H, Zhang L, Zhong Y, Yan X, Sui X (2018) Temperature-responsive cellulose sponge with switchable pore size: Application as a water flow manipulator. Mater Lett 210: . https://doi.org/10.1016/j.matlet.2017.09.012

25. Martins VC, Cardoso FA, Germano J, Cardoso S, Sousa L, Piedade M, Freitas PP, Fonseca LP (2009) Femtomolar limit of detection with a magnetoresistive biochip. Biosens Bioelectron 24:2690-2695 . https://doi.org/10.1016/j.bios.2009.01.040

26. Martins SAM, Martins VC, Cardoso FA, Germano J, Rodrigues M, Duarte C, Bexiga R, Cardoso S, Freitas PP (2019) Biosensors for on-farm diagnosis of mastitis. Front Bioeng Biotechnol 7: . https://doi.org/10.3389/fbioe.2019.00186

27. Graham DL, Ferreira HA, Freitas PP (2004) Magnetoresistive-based biosensors and biochips. Trends Biotechnol. 22

28. Freitas PP, Cardoso FA, Martins VC, Martins SAM, Loureiro J, Amaral J, Chaves RC, Cardoso S, Fonseca LP, Sebastião AM, Pannetier-Lecoeur M, Fermon C (2012) Spintronic platforms for biomedical applications. Lab Chip 12

29. Armbruster DA, Pry T (2008) Limit of blank, limit of detection and limit of quantitation. Clin Biochem Rev 29 Suppl 1:S49-52

30. Trantidou T, Elani Y, Parsons E, Ces O (2017) Hydrophilic surface modification of pdms for droplet microfluidics using a simple, quick, and robust method via pva deposition. Microsystems Nanoeng 3:16091 . https://doi.org/10.1038/micronano.2016.91

31. Shakeri A, Khan S, Didar TF (2021) Conventional and emerging strategies for the fabrication and functionalization of PDMS-based microfluidic devices. Lab Chip 21:3053-3075 . https://doi.org/10.1039/D1LC00288K

32. Hasanuzzaman M, Rafferty A, Sajjia M, Olabi A-G (2016) Properties of Glass Materials. Ref Modul Mater Sci Mater Eng 1-12 . https://doi.org/10.1016/b978-0-12803581-8.03998-9

33. Tsige M, Soddemann T, Rempe SB, Grest GS, Kress JD, Robbins MO, Sides SW, Stevens MJ, Webb E (2003) Interactions and structure of poly(dimethylsiloxane) at silicon dioxide surfaces: Electronic structure and molecular dynamics studies. J Chem 
Phys 118:5132-5142 . https://doi.org/10.1063/1.1545091

34. Vlachopoulou ME, Petrou PS, Kakabakos SE, Tserepi A, Beltsios K, Gogolides E (2009) Effect of surface nanostructuring of PDMS on wetting properties, hydrophobic recovery and protein adsorption. Microelectron Eng 86:1321-1324 . https://doi.org/10.1016/j.mee.2008.11.050

35. Vlassov S, Oras S, Antsov M, Sosnin I, Polyakov B, Shutka A, Dorogin LM, Roberts C, Graham A, Nemer M, Phinney L, Garcia R, Stirrup E, Russell MT, Pingree LSC, Hersam MC, Marks TJ, Xu W, Chahine N, Sulchek T, Klasner SA, Metto EC, Roman GT, Culbertson CT, Lötters JC, Olthuis W, Veltink PH, Bergveld P (2011) Physical Properties of Low-Molecular Weight Polydimethylsiloxane Fluids. Langmuir 25:

36. Yao M, Fang J (2012) Hydrophilic PEO-PDMS for microfluidic applications. J Micromechanics Microengineering 22: . https://doi.org/10.1088/0960$1317 / 22 / 2 / 025012$

37. Klasner SA, Metto EC, Roman GT, Culbertson CT (2009) Synthesis and characterization of a poly(dimethylsiloxane)-poly (ethylene oxide) block copolymer for fabrication of amphiphilic surfaces on microfluidic devices. Langmuir 25: . https://doi.org/10.1021/la900920q

38. Emoto A, Kobayashi T, Noguchi N, Fukuda T (2014) Tailoring adhesive forces between poly(dimethylsiloxane) and glass substrates using poly(vinyl alcohol) primers. J Appl Polym Sci 131:1-7 . https://doi.org/10.1002/app.39927

39. Yu K, Han Y (2006) A stable PEO-tethered PDMS surface having controllable wetting property by a swelling-deswelling process. Soft Matter 2:705-709 . https://doi.org/10.1039/b602880m

40. Iwasaki S, Kawasaki H, Iwasaki Y (2019) Label-Free Specific Detection and Collection of C-Reactive Protein Using Zwitterionic Phosphorylcholine-PolymerProtected Magnetic Nanoparticles. Langmuir 35: . https://doi.org/10.1021/acs.langmuir.8b01007

41. Nirala NR, Harel Y, Lellouche JP, Shtenberg G (2020) Ultrasensitive haptoglobin biomarker detection based on amplified chemiluminescence of magnetite nanoparticles. J Nanobiotechnology 18: . https://doi.org/10.1186/s12951-019-0569-9 
42. Silva Y, Leira R, Tejada J, Lainez JM, Castillo J, Dávalos A (2005) Molecular signatures of vascular injury are associated with early growth of intracerebral hemorrhage. Stroke 36:86-91 . https://doi.org/10.1161/01.STR.0000149615.51204.0b

43. Castellanos M, Sobrino T, Millán M, García M, Arenillas J, Nombela F, Brea D, Perez De La Ossa N, Serena J, Vivancos J, Castillo J, Dávalos A (2007) Serum cellular fibronectin and matrix metalloproteinase-9 as screening biomarkers for the prediction of parenchymal hematoma after thrombolytic therapy in acute ischemic stroke: A multicenter confirmatory study. Stroke 38: . https://doi.org/10.1161/STROKEAHA.106.481556

44. NCBI (2021) MMP9 matrix metallopeptidase 9 [ Homo sapiens (human) ]. In: Natl. Cent. Biotechnol. Information, U.S. Natl. Libr. Med. https://www.ncbi.nlm.nih.gov/gene/4318. Accessed 1 Jun 2021

45. Bradshaw AD (2016) The Extracellular Matrix. In: Encyclopedia of Cell Biology. Elsevier Ltd., pp 694-703

46. Zordan MD, Grafton MMG, Acharya G, Reece LM, Aronson AI, Park K, Leary JF (2009) A microfluidic-based hybrid SPR/molecular imaging biosensor for the multiplexed detection of foodborne pathogens. Front Pathog Detect From Nanosensors to Syst 7553:716706 . https://doi.org/10.1117/12.808316

47. Lee TY, Shin Y, Park MK (2014) A simple, low-cost, and rapid device for a DNA methylation-specific amplification/detection system using a flexible plastic and silicon complex. Lab Chip 14:4220-4229 . https://doi.org/10.1039/c4lc00804a

48. Hou Y, Tang W, Qi W, Guo X, Lin J (2020) An ultrasensitive biosensor for fast detection of Salmonella using 3D magnetic grid separation and urease catalysis. Biosens Bioelectron 157:112160 . https://doi.org/10.1016/j.bios.2020.112160

49. Sofla A, Cirkovic B, Hsieh A, Miklas JW, Filipovic N, Radisic M (2013) Enrichment of live unlabelled cardiomyocytes from heterogeneous cell populations using manipulation of cell settling velocity by magnetic field. Biomicrofluidics 7: . https://doi.org/10.1063/1.4791649

50. Kim J, Lee HH, Steinfeld U, Seidel H (2009) Fast capturing on micromagnetic cell sorter. IEEE Sens J 9:908-913 . https://doi.org/10.1109/JSEN.2009.2024863 
51. Hermann CA, Mayer M, Griesche C, Beck F, Baeumner AJ (2021) Microfluidicenabled magnetic labelling of nanovesicles for bioanalytical applications. Analyst 146:997-1003 . https://doi.org/10.1039/d0an02027c

52. Hoshino K, Huang YY, Lane N, Huebschman M, Uhr JW, Frenkel EP, Zhang X (2011) Microchip-based immunomagnetic detection of circulating tumor cells. Lab Chip 11:3449-3457 . https://doi.org/10.1039/c1lc20270g

53. Bhuvanendran Nair Gourikutty S, Chang CP, Puiu PD (2016) Microfluidic immunomagnetic cell separation from whole blood. J Chromatogr B Anal Technol Biomed Life Sci 1011:77-88 . https://doi.org/10.1016/j.jchromb.2015.12.016

54. Otieno BA, Krause CE, Latus A, Chikkaveeraiah B V., Faria RC, Rusling JF (2014) On-line protein capture on magnetic beads for ultrasensitive microfluidic immunoassays of cancer biomarkers. Biosens Bioelectron 53:268-274 . https://doi.org/10.1016/j.bios.2013.09.054

55. Grafton MM, Zordan MD, Chuang H-S, Rajdev P, Reece LM, Irazoqui PP, Wereley ST, Byrnes R, Todd P, Leary JF (2010) Portable microfluidic cytometer for whole blood cell analysis. Microfluid BioMEMS, Med Microsystems VIII 7593:75930M . https://doi.org/10.1117/12.842932

56. Vojtíšek M, Iles A, Pamme N (2010) Rapid, multistep on-chip DNA hybridisation in continuous flow on magnetic particles. Biosens Bioelectron 25:2172-2176 . https://doi.org/10.1016/j.bios.2010.01.034

57. Liang L, Xuan X (2012) Diamagnetic particle focusing using ferromicrofluidics with a single magnet. Microfluid Nanofluidics 13:637-643 . https://doi.org/10.1007/s10404012-1003-x

58. Zeng J, Chen C, Vedantam P, Tzeng TR, Xuan X (2013) Magnetic concentration of particles and cells in ferrofluid flow through a straight microchannel using attracting magnets. Microfluid Nanofluidics 15:49-55 . https://doi.org/10.1007/s10404-012$1126-0$

59. Agarwal S, Wang B, Yang H, Dhanapal P, Shen Y, Wang J, Wang H, Zhao J, Li RW (2018) Spin-valve-like magnetoresistance in a Ni-Mn-In thin film. Phys Rev B 97:1-7 . https://doi.org/10.1103/PhysRevB.97.214427 
60. Iqbal MZ, Iqbal MW, Siddique S, Khan MF, Ramay SM (2016) Room temperature spin valve effect in NiFe/WS2/Co junctions. Sci Rep 6:2-7 .

https://doi.org/10.1038/srep21038

61. Tsai HY, Hsu FH, Lin YP, Fuh CB (2006) Separation method based on affinity reaction between magnetic and nonmagnetic particles for the analysis of particles and biomolecules. J Chromatogr A 1130:227-231 .

https://doi.org/10.1016/j.chroma.2006.05.045

62. Tsai HY, Hsieh YC, Su YM, Chan JR, Chang YC, Fuh CB (2011) Effects of particle characteristics on magnetic immunoassay in a thin channel. Biosens Bioelectron 28:38-43 . https://doi.org/10.1016/j.bios.2011.06.038

63. Zeng L, Chen X, Du J, Yu Z, Zhang R, Zhang Y, Yang H (2021) Label-free separation of nanoscale particles by an ultrahigh gradient magnetic field in a microfluidic device. Nanoscale 13:4029-4037 . https://doi.org/10.1039/d0nr08383f 


\section{Author Information}

Briliant Adhi Prabowo - orcid.org/0000-0002-7543-5143

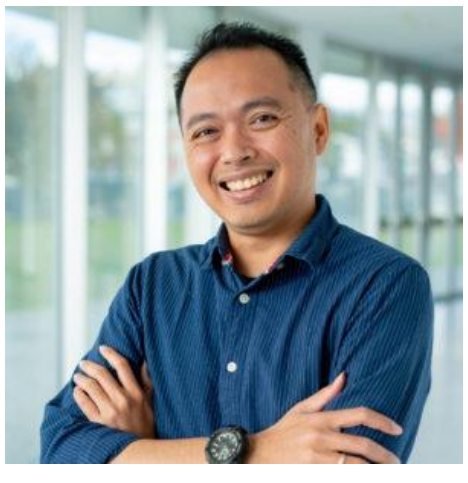

Briliant joined INL in July 2019 in the Nanodevice group. His research is related to the development of biosensing devices. He was a research fellow at the Indonesian Institute of Sciences (LIPI) at the Research Center for Electronics and Telecommunications LIPI. He was also a postdoctoral fellow at Organic Electro-Optical Device Group at Chang Gung University, Taiwan, working on portable SPR sensor development for clinical sample analysis in collaboration with Chang Gung Memorial Hospital, Taiwan.

He received his Ph.D. degree in the Department of Electronics Engineering from Chang Gung University, Taiwan in 2017. His research was related to the development of portable SPR biosensors for biomedical applications. He received his Master's degree in Semiconductor Technology from Asia University, Taiwan, where his project was joint research with Taiwan Semiconductor Manufacturing Co. (TSMC) and Vanguard International Semiconductor (VIS), in the field of reliability of power devices and AlGaN/GaN HEMTs. His bachelor's degree was in Electrical Engineering obtained from Soegijapranata Catholic University, Indonesia.

Elisabete Fernandes - orcid.org/0000-0003-4558-7047

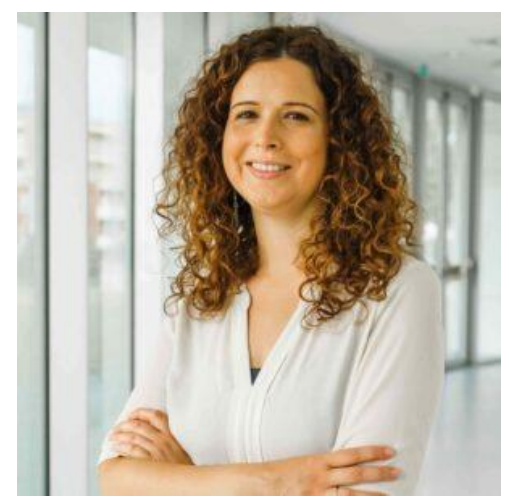

Elisabete Fernandes is an assay development scientist in the biosensors field, and is currently, a staff researcher in the Nanodevices Group at the International Iberian Nanotechnology Laboratory (INL). At INL, her main role is related to the development of monoplex and multiplex assay formats, surface functionalization, the applicability of biosensors to the multiplex detection of medical biomarkers, and the clinical validation protocols. She received a Ph.D. degree in Chemical and Biological Engineering from the University of Minho, Portugal, in 2013. The Ph.D. research was focused on the development of a biosensor using bacteriophages (lytic and filamentous) as biorecognition elements. Part of the work was developed at the University of Auburn, USA, and at the University of Leuven, Belgium. She received a national grant (FCT) under the Ph.D., following a Marie Curie Fellowship as part of an EU-funded 
project for cancer diagnosis. Elisabete has published 8 peer-reviewed papers in scientific journals of Quartile 1 (4 in the top 5\% and 3 in the top 10\% - based on Scimago Journal Ranking), 2 in Quartile 2, and 1 book chapter in an international scientific book. Author and co-author of 23 oral communications and 15 posters presented in international scientific seminars, workshops, and conferences. Elisabete is co-supervisor of $3 \mathrm{Ph}$.D. students, and up to now, co-supervised 4 Master's students. She is the coordinator of a project related to a Fully Integrated Magnetoresistive Biochip Platform for Stroke Patient Stratification (FIM4Stroke) through a National funded program. Since 2007, Elisabete has participated as a team member in more than 8 National, Iberian and European projects. Elisabete major skills are related to (1) the use of different types of biomarkers for biosensor approaches, like microvesicles, antibodies, phage, and inflammatory protein markers; (2) functionalization of gold and graphene surfaces and cellulose membranes; (3) functionalization of nanoparticles: bifunctional linkers and bioconjugation on gold, polystyrene, and magnetic nanoparticles; (3) use of magnetoresistive platforms (based on spin-valve sensors), magnetoelastic sensors, and lateral-flow-assays, and (4) technical skills in biotechnology. Besides that, Elisabete is a multidisciplinary researcher with participation in pedagogical projects (national and international) with filiation to the National Geographic as a certified educator and responsible for a volunteer project related to scientific literacy at INL.

\section{Paulo Freitas - orcid.org/0000-0003-0015-1186}

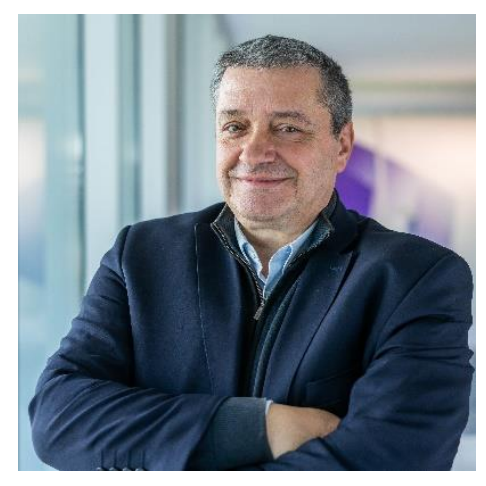

Paulo Freitas has a BSc in Physics from the University of Porto and a Ph.D. in Physics from Carnegie Mellon University (1986). After his Ph.D. at Carnegie Mellon University, he was a postdoctoral Research Fellow at the IBM Watson Research Center, Yorktown Heights, New York, USA (1986-87). From 1990 to 2000, he was Director of the Solid State Technology Group at INESC and, since 2000, Director of INESC-MN. Professor Freitas has been a full professor of Physics at the Instituto Superior Técnico since 2003, administering the Department of Physics since 2006. In 2007, he joined the Installation Commission of the International Iberian Nanotechnology Institute (INL) and was appointed Deputy Director-General in 2009.

Professor Freitas received several awards and distinctions, namely: the Fundação Calouste Gulbenkian Prize in the area of Nanotechnologies, as Ph.D. supervisor of H. Ferreira (2004); the Prémio Excelência, from the Portuguese Foundation for Science and Technology (2005- 
2006); the 2nd Finalist of Descartes Prize for Research (2007), awarded by The European Commission; and a Distinguished Lecturer award from the IEEE - Institute of Electrical and Electronics Engineers, USA (2008).

Professor Freitas' current research interests include GMR heads for ultra-high density recording, spin-dependent tunneling junctions, non-volatile memories, magnetic multilayers, thin films, micro magnetism, transport phenomena, GMR sensors, bioelectronics, and biosensors. He is the author of more than 500 publications in peer-reviewed journals. 


\section{Graphical Abstract}

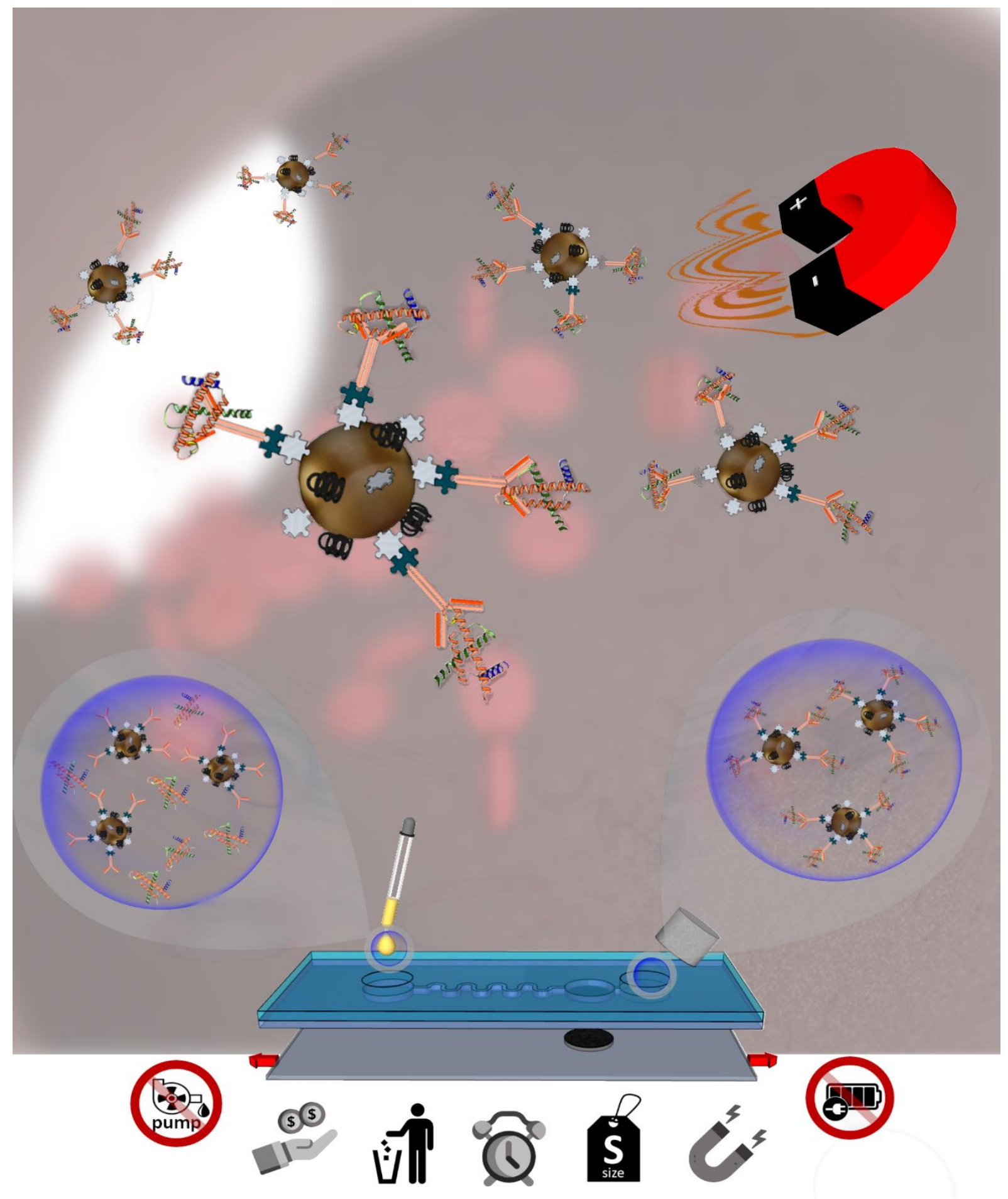




\section{Figures and Captions}

\section{Figure 1}
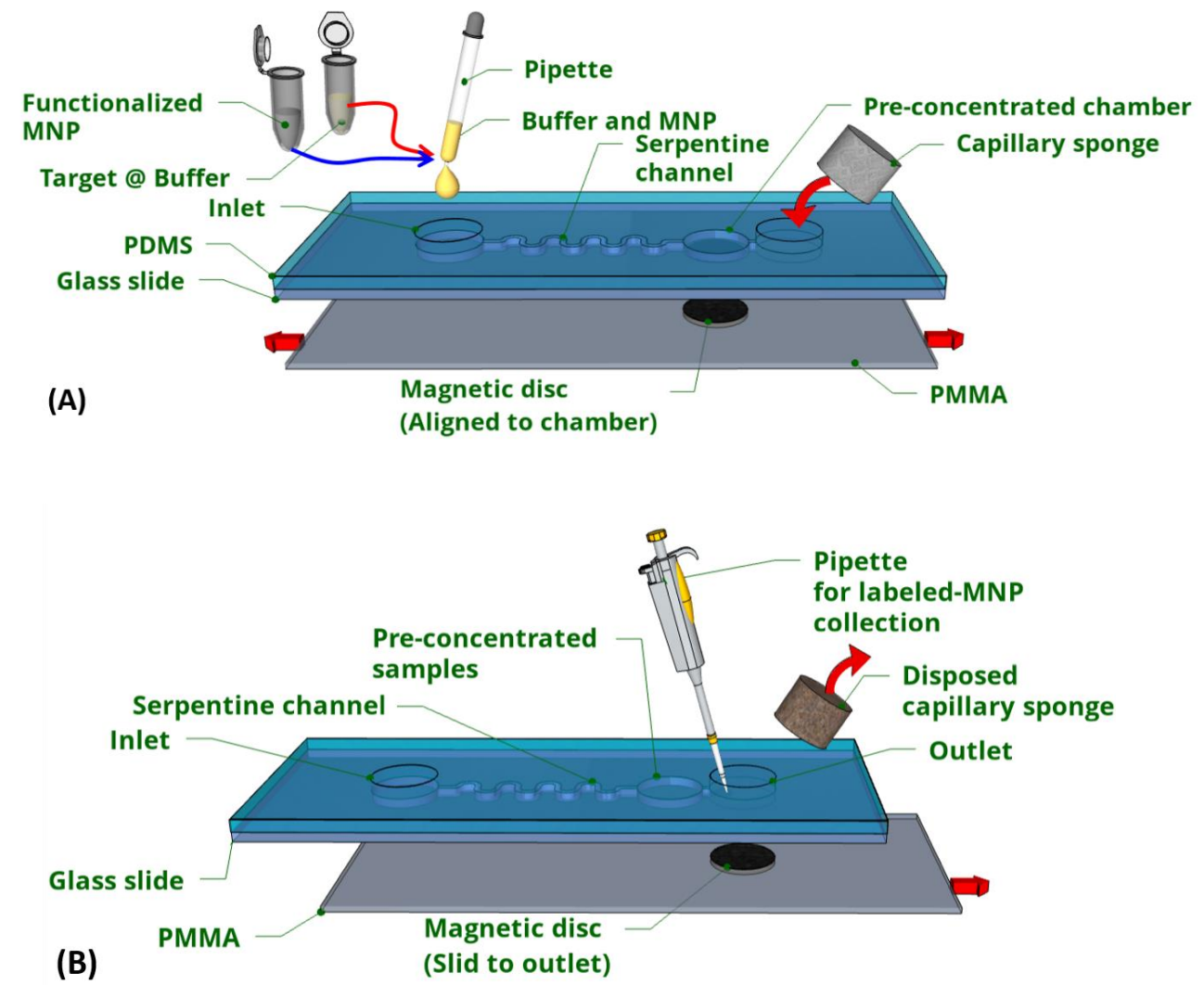

Fig. 1 Experimental design of the MNP labeling of the interested protein biomarkers on a microfluidic chip using capillary force and magnetic concentrator. Total size of the chip is length: $75 \mathrm{~mm}$; width: 25 $\mathrm{mm}$; and height: $5 \mathrm{~mm}$. (A) Sample loading on the inlet followed by the mixing at the serpentine channel until to fulfil the pre-concentrated chamber, and the capillary sponge aligned to the outlet. (B) After the waste sample is fully absorbed, the sponge is discarded; then, the magnetic disc is slid to the outlet, followed by concentrated sample collection process up to $10 \mu \mathrm{L}$. (The schematic figures is for illustration purpose and not in real scale to the real device.) 
Figure 2
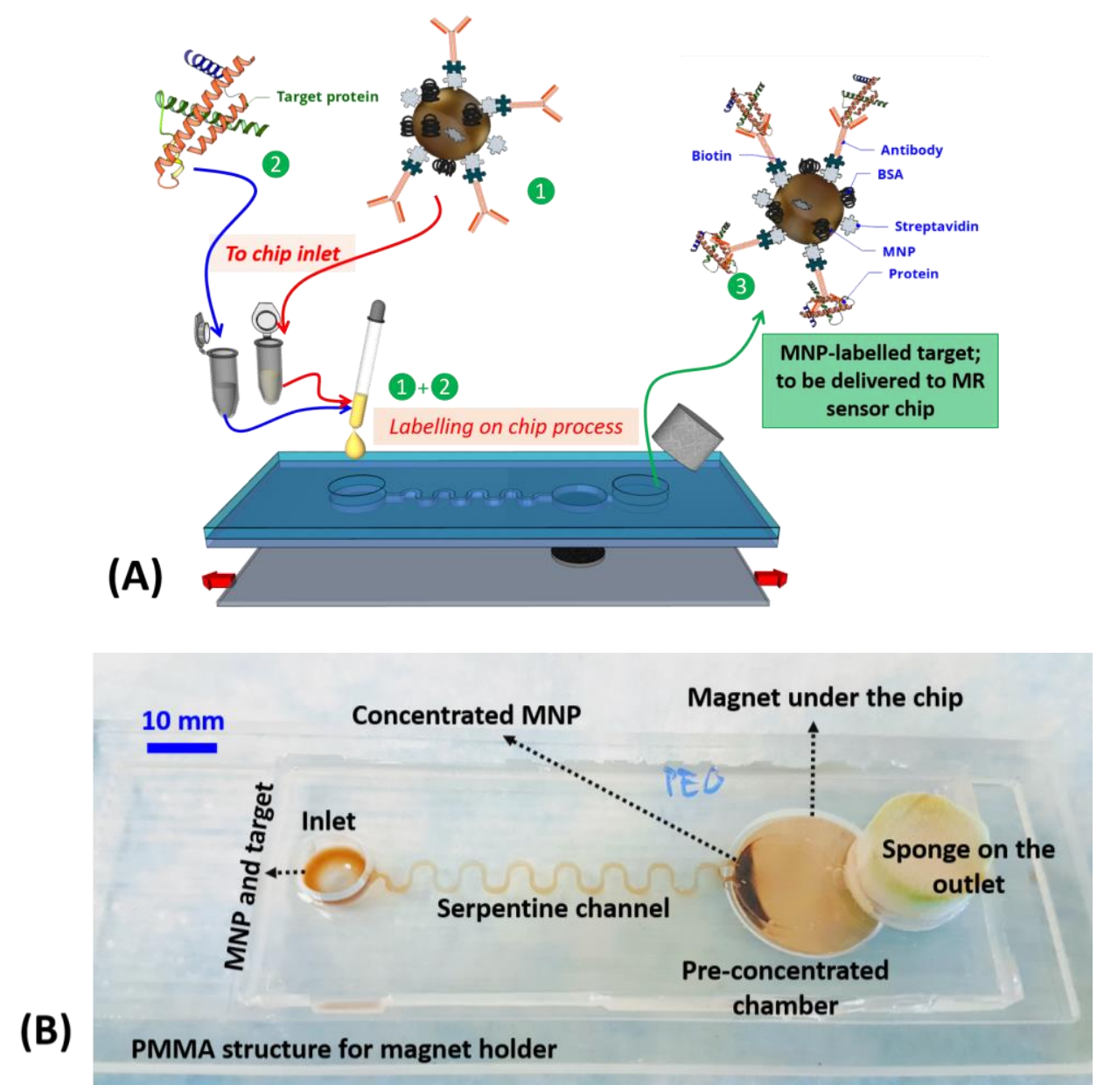

Fig. 2(A) Schematic of the magnetic labeling on-chip. Sample loading (1+2) of (1) functionalized MNPs with the (2) protein biomarker, and after the labeling on chip, the end sample (3) MNPs with the interest biomarker captured. (B) The picture of the proposed microfluidic chip during the labeling process of protein biomarkers. 
Figure 3
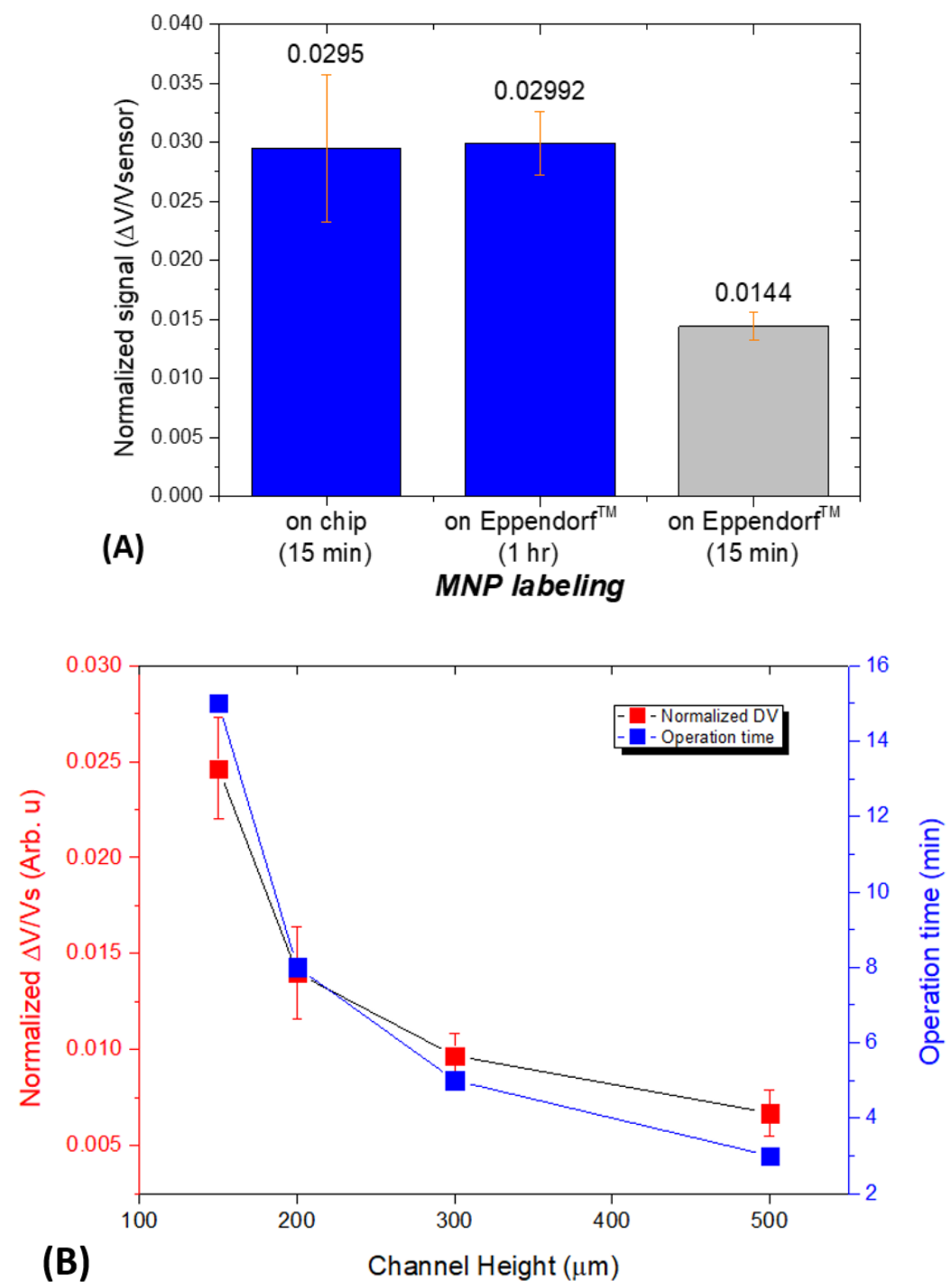

Fig. 3 (A) Sensor signals representing the binding efficiency of magnetic labeling on-chip of c-Fn compared to the conventional labeling on $1.5 \mathrm{~mL}^{\text {Eppendorf }}{ }^{\mathrm{TM}}$ tube. The undiluted MNPs were exposed to $10 \mu \mathrm{g} / \mathrm{mL}$ of c-Fn. (B) The device characteristics by the different channel heights and its correlation to the operation time and labeling performance. The moulding for channel characteristics were fabricated using 3D (three dimensional) printing technology (Method S1 in supplementary materials). 
Figure 4
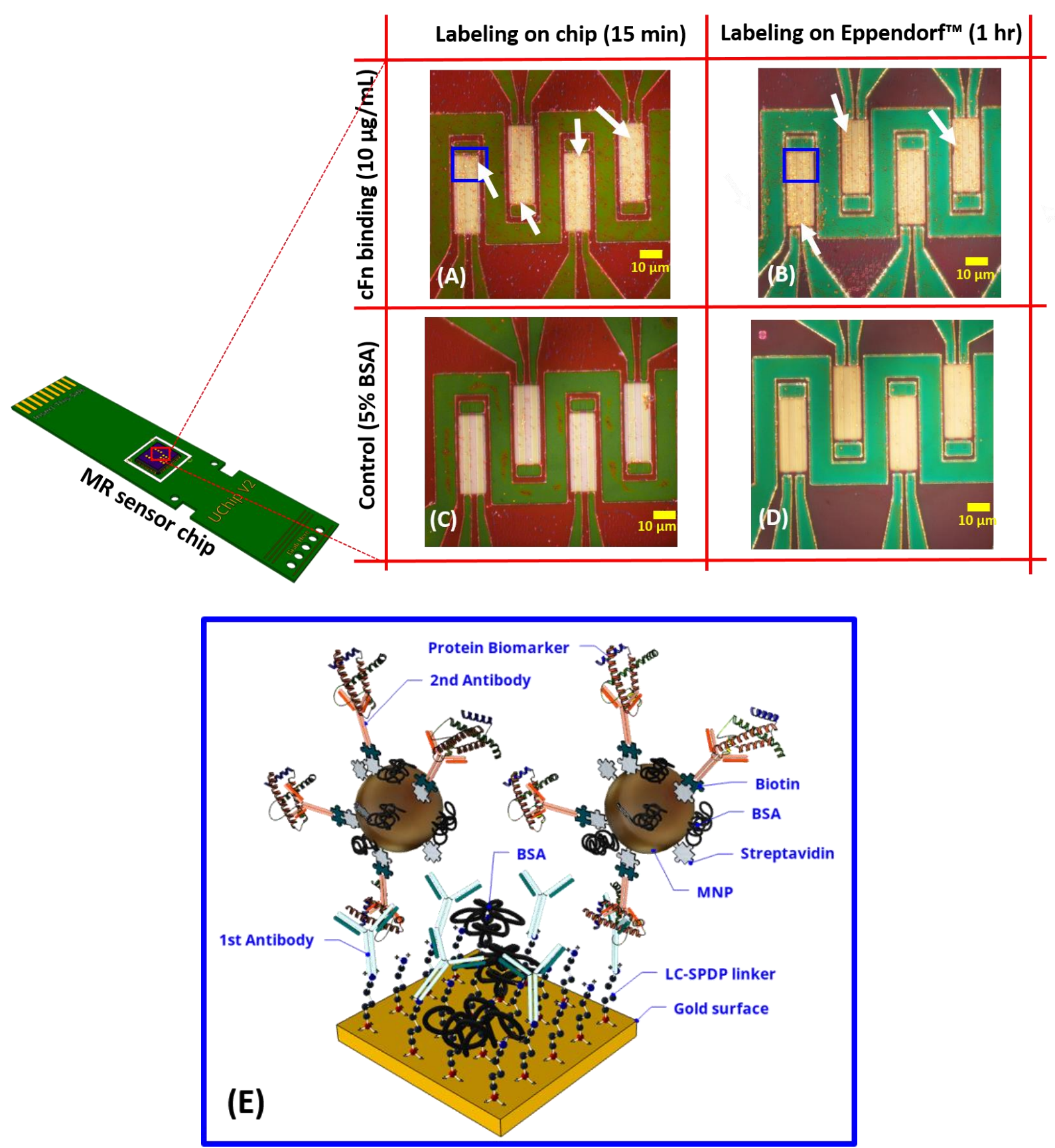

Fig. 4 Optical microscope representative images (Wide-Field Upright Fluorescence Microscope - Nikon Ni-E) of MNPs binding on the spin valve sensor surface (gold color), either using the microfluidic chip (A) or using the conventional magnetic labeling on $1.5 \mathrm{~mL}$ Eppendorf ${ }^{\mathrm{TM}}$ tube (B). (C) and (D) are the control regions of the the spin valve sensor, which were blocked with 5\% of BSA. The arrow shows the MNPs clusters binds to the sensor surface. The illustration of the sandwich binding assay in MR sensing region for target (square blue) is depicted in (E). 
Figure 5
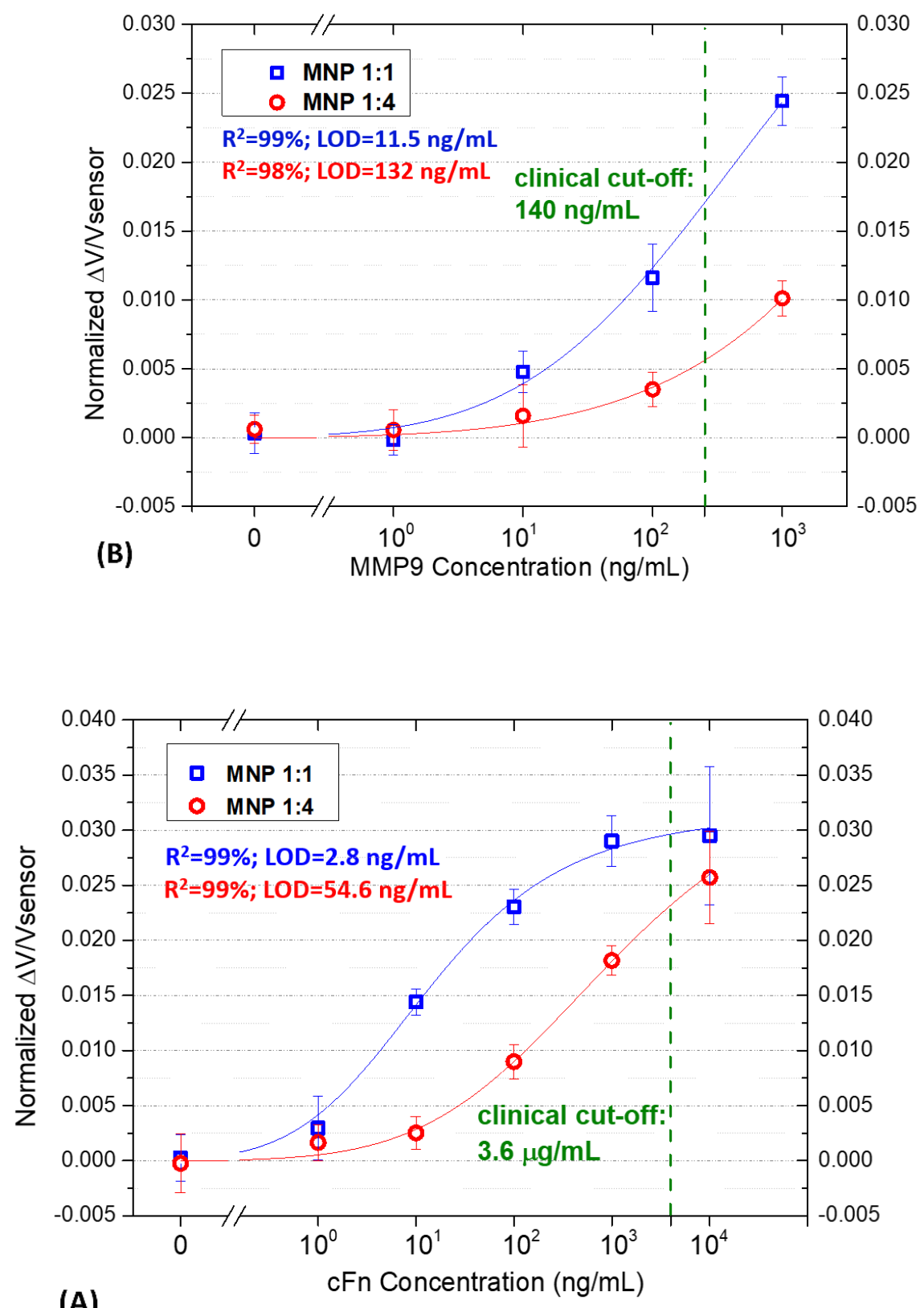

(A)

Fig. 5 Calibration curves for (A) c-Fn and (B) MMP9 in an MR biosensor platform using a magnetic labeling on-chip. The dashed green lines are the remarks of the clinical cutoff value for c-Fn and MMP9 in the blood of stroke patients. 
Table and captions

Table 1 Hydrophilicity treatments applied to the microfluidic chip to enhance the capillary sample flow and lifetime.

\begin{tabular}{|c|c|c|c|c|}
\hline & As fabricated & PVA-chip & PEO-m-Chip & PEO-chip \\
\hline $\begin{array}{l}\text { Hydrophilic } \\
\text { Treatment }\end{array}$ & $\begin{array}{c}\text { Plasma } \mathrm{O}_{2} \\
\text { during } \\
\text { bonding }\end{array}$ & $\begin{array}{c}\text { Channel } \\
\text { passivation }\end{array}$ & $\begin{array}{l}\text { Mix with the } \\
\text { whole PDMS }\end{array}$ & $\begin{array}{c}\text { Channel } \\
\text { passivation }\end{array}$ \\
\hline Temperature & $\mathrm{RT}$ & $40-100{ }^{\circ} \mathrm{C}$ & $\mathrm{RT}$ & $65^{\circ} \mathrm{C}$ \\
\hline Activation time & $2 \mathrm{~min}$ & $8 \mathrm{hr}$ & $\begin{array}{c}\text { No additional } \\
\text { time }\end{array}$ & $8 \mathrm{hr}$ \\
\hline $\begin{array}{c}\text { Channel flow } \\
\text { rate }\end{array}$ & $30-50 \mu \mathrm{L} / \mathrm{min}$ & $4.8 \mu \mathrm{L} / \mathrm{min}$ & $27 \mu \mathrm{L} / \min$ & $25 \mu \mathrm{L} / \min$ \\
\hline Advantage & $\begin{array}{l}\text { Simple, high } \\
\text { flow rate }\end{array}$ & Strong bonding & Simple process & $\begin{array}{l}\text { Medium flow } \\
\text { rate }\end{array}$ \\
\hline Drawback & Short lifetime & $\begin{array}{l}\text { Very low } \\
\text { flowrate }\end{array}$ & $\begin{array}{l}\text { Weak bonding, } \\
\text { easy leakage }\end{array}$ & Activation time \\
\hline $\begin{array}{l}\text { Hydrophilicity } \\
\text { lifetime }\end{array}$ & 1-2 days & 2 months & 2 months & 2 months \\
\hline
\end{tabular}


Table 2 The comparison of related published works of the microfluidic utilizing magnet for labeling or particle separation purpose.

\begin{tabular}{|c|c|c|c|c|c|c|c|}
\hline No & Technical remarks & $\begin{array}{c}\text { Target/ } \\
\text { biomarkers }\end{array}$ & $\begin{array}{l}\text { Pump } \\
\text { Free }\end{array}$ & $\begin{array}{l}\text { Battery/ } \\
\text { Power free }\end{array}$ & $\begin{array}{c}\text { Disposable } \\
\text { feature }\end{array}$ & $\begin{array}{c}\text { Operation } \\
\text { time }\end{array}$ & Ref. \\
\hline 1 & $\begin{array}{l}\text { Integrated to SPR and fluorescence } \\
\text { imaging, multiplexed design. }\end{array}$ & E. coli $\mathrm{O} 157: \mathrm{H} 7$ & No & No & Partly & $\mathrm{n} / \mathrm{a}$ & {$[46]$} \\
\hline 2 & $\begin{array}{l}\text { Isothermal solid-phase amplification } \\
\text { and detection of DNA methylation }\end{array}$ & DNA & No & No & Partly & $65 \mathrm{~min}$ & [47] \\
\hline 3 & $\begin{array}{c}\text { 3D magnetic grid separation and } \\
\text { urease catalysis }\end{array}$ & Salmonella cells & No & No & Partly & $1 \mathrm{~h}$ & [48] \\
\hline 4 & $\begin{array}{c}\text { Disposable electrochemical } \\
\text { immunosensor for flow injection } \\
\text { immunoassay }\end{array}$ & $\begin{array}{l}\text { carcinoembryon } \\
\text { ic antigen } \\
\text { (CEA), IgG }\end{array}$ & No & No & Partly & $<10 \min$ & {$[61,62]$} \\
\hline 5 & $\begin{array}{l}\text { Label free, capturing live } \\
\text { cardiomyocytes }\end{array}$ & cardiomyocytes & No & No & Partly & $>20 \mathrm{~min}$ & [49] \\
\hline 6 & $\begin{array}{c}\text { Micromagnetic Cell Sorter, rapid } \\
\text { capture target }\end{array}$ & $\begin{array}{c}\text { CD3+ } \\
\text { T lymphocytes }\end{array}$ & No & No & Partly & $20 \mathrm{~s}$ & {$[50]$} \\
\hline 7 & $\begin{array}{l}\text { Ultrahigh gradient magnetic field in a } \\
\text { microfluidic device for particle target } \\
\text { separation, negative magnetophoretic } \\
\text { technique }\end{array}$ & $\mathrm{n} / \mathrm{a}$ & No & No & Partly & $\mathrm{n} / \mathrm{a}$ & {$[63]$} \\
\hline 8 & $\begin{array}{l}\text { Magnetic labeling of nanovesicles on } \\
\text { microfluidic chip }\end{array}$ & liposomes & No & No & Partly & $15 \mathrm{~min}$ & {$[51]$} \\
\hline 9 & $\begin{array}{l}\text { Microchip-based immunomagnetic to } \\
\text { capture CTC }\end{array}$ & $\begin{array}{l}\text { Cancer cell } \\
\text { (COLO205 and } \\
\text { SKBR3) }\end{array}$ & No & No & Partly & $15 \mathrm{~min}$ & {$[52]$} \\
\hline 10 & $\begin{array}{l}\text { Microfluidic for cell separation from } \\
\text { blood }\end{array}$ & $\begin{array}{l}\text { White blood cell } \\
\text { (WBC) }\end{array}$ & No & No & Partly & $4 \min$ & [53] \\
\hline 11 & $\begin{array}{l}\text { Non-lithography microfluidic, } \\
\text { Multiplex cancer biomarker screening }\end{array}$ & IL-6 and IL-8 & No & No & Partly & $30 \mathrm{~min}$ & [54] \\
\hline 12 & $\begin{array}{l}\text { Portable, fully integrated, and } \\
\text { miniaturized cytometer chip }\end{array}$ & $\begin{array}{l}\text { WBC, } \text { Red } \\
\text { blood cell } \\
(\mathrm{RBC})\end{array}$ & No & No & Partly & $5 \min$ & {$[55]$} \\
\hline 13 & DNA hybridization on chip, & DNA & No & No & Partly & $1 \mathrm{~min}$ & {$[56]$} \\
\hline 14 & $\begin{array}{l}\text { Magnetophoresis for particle and cells } \\
\text { separation }\end{array}$ & $\begin{array}{l}\text { Polystyrene and } \\
\text { Saccharomyces } \\
\text { cerevisiae }\end{array}$ & Yes & Yes & Whole parts & $10 \mathrm{~min}$ & [58] \\
\hline 15 & $\begin{array}{l}\text { 3D focusing Ferromicrofluidics with a } \\
\text { single magnet }\end{array}$ & $\mathrm{n} / \mathrm{a}$ & Yes & Yes & Whole parts & $\mathrm{n} / \mathrm{a}$ & {$[57]$} \\
\hline 16 & $\begin{array}{l}\text { Capillary microfluidic, protein } \\
\text { magnetic labeling and tailoring }\end{array}$ & c-Fn, MMP9 & Yes & Yes & Whole parts & $15 \mathrm{~min}$ & $\begin{array}{l}\text { This } \\
\text { work }\end{array}$ \\
\hline
\end{tabular}

